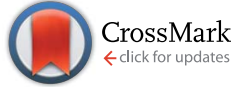

Cite this: Chem. Sci., 2017, 8, 2795

Received 5th September 2016 Accepted 16th December 2016

DOI: $10.1039 / \mathrm{c} 6 \mathrm{sc} 03970 \mathrm{~g}$

www.rsc.org/chemicalscience

\section{A practical strategy to design and develop an isoform-specific fluorescent probe for a target enzyme: CYP1A1 as a case study $\dagger$}

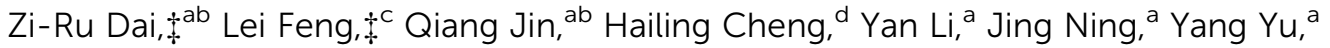 \\ Guang-Bo Ge, ${ }^{\star a c}$ Jing-Nan Cui ${ }^{c}$ and Ling Yang*a
}

The development of isoform-specific probe(s) for a target enzyme with multiple homologs is always challenging. Herein, a practical strategy was used to design and develop an isoform-specific probe for CYP1A1, a key cytochrome P450 isoenzyme involved in xenobiotic metabolism and bioactivation. On the basis of the subtle differences in 3D structure and substrate preference between CYP1A1 and its homolog CYP1A2, we proposed that it was possible to design a CYP1A1-specific probe via local modification of the reaction site on known CYP1A substrates. To validate this hypothesis, 4-hydroxy1,8-naphthalimide $(\mathrm{HN})$ was selected as the basic fluorophore due to its excellent optical properties, while a series of $\mathrm{O}$-alkylated $\mathrm{HN}$ derivatives were prepared to evaluate their specificity towards CYP1A1. Our results revealed that the introduction of a chloroethyl to $\mathrm{HN}$ could get the best isoform selectivity towards CYP1A1 over other CYPs including CYP1A2. The newly developed probe NBCeN exhibited excellent specificity, high sensitivity, and a ratiometric fluorescence response following CYP1A1catalyzed O-dechloroethylation. NBCeN was successfully used to real-time monitor the activity of CYP1A1 in complex biological samples and to rapidly screen CYP1A1 modulators in living systems. NBCeN could also be used for two-photon imaging of intracellular CYP1A1 in living cells and tissues with high ratiometric imaging resolution and deep tissue penetration. All these findings demonstrated that local modification of non-specific substrates was a practical strategy to develop an isoform-specific probe for a target isoenzyme, while NBCeN could serve as a specific imaging tool to explore the biological functions of CYP1A1 in complex biological systems.

\section{Introduction}

The human proteome projects have uncovered more than 20000 proteins distributed in human tissues and cells. ${ }^{\mathbf{1}}$ It is noteworthy that a large fraction ( $72 \%)$ of human genes encode multiple variants with similar but different protein sequences, which means that most human proteins have more than one isoform. ${ }^{2}$ As an important class of human proteins, enzymes catalyze more than 6000 reactions in the human body and play very important roles in both exogenous and endogenous metabolism, and thus are recognized as key factors affecting human physiological and pathological processes. ${ }^{3}$ It is well-

${ }^{a}$ Dalian Institute of Chemical Physics, Chinese Academy of Sciences, Dalian, China. E-mail:yling@dicp.ac.cn; geguangbo@dicp.ac.cn

${ }^{b}$ Graduate School of Chinese Academy of Sciences, Beijing, China

${ }^{c}$ State Key Laboratory of Fine Chemicals, Dalian University of Technology, Dalian, China

${ }^{d}$ Cancer Institute, The Second Hospital of Dalian Medical University, Dalian, China $\dagger$ Electronic supplementary information (ESI) available: Detailed experimental procedures and characterization of compounds. See DOI: 10.1039/c6sc03970g \$ These authors contributed equally. known that deciphering the physiological functions of target enzyme(s) requires specific tools (such as probe substrates and selective inhibitors) to profile and perturb their activities in native biological systems. ${ }^{4}$ However, the members belonging to an enzyme subfamily always have similar structures and display very minor differences in function (such as reaction types and substrate specificity), thus it is very hard for biochemists to find isoform-specific probes for a target enzyme with multiple homologs. ${ }^{5}$ Although several methods including antibody-based assays and mass spectrometrybased proteomic techniques can be used to quantify the levels of many enzyme isoforms in various biological samples, these methods cannot be used to characterise the biological functions of a target enzyme. ${ }^{6}$ Although many activity-based probes including optical and non-optical substrates have been designed and used to directly measure the enzymatic activities of target enzyme(s) in various biological systems, almost all reported probes are not designed by targeting a specific isoform. ${ }^{7}$ Therefore, it is urgently necessary to develop a practical strategy to guide the rational design of isoform specific probes for a target enzyme. 
The cytochrome P450 (CYP) superfamily is the largest enzyme family in mammals consisting of over 750 hemecontaining membrane proteins located primarily in the endoplasmic reticulum (ER). ${ }^{8}$ In mammals, CYP monooxygenases catalyze the oxidative metabolism of endogenous compounds and various xenobiotics, leading to the metabolic activation and detoxification of a wide variety of environmental pollutants and drugs. ${ }^{9}$ The CYP1A subfamily plays critical roles in the metabolic activation of a great variety of procarcinogenic compounds to endotoxic intermediates or ultimate carcinogens, and thus has attracted increasing attention in the fields of toxicology and oncology. ${ }^{10}$ In humans, the CYP1A subfamily consists of two major isoforms including CYP1A1 and CYP1A2. ${ }^{11}$ CYP1A2 is abundantly expressed in the liver, while CYP1A1 is expressed in hepatic and extrahepatic tissues including the lung salivary gland and the gastrointestinal tract. ${ }^{\mathbf{2}}$ Previous studies have clearly shown that CYP1A1 contributes to tumour formation and cancer susceptibilities. ${ }^{13}$ To better understand the biological and physiological roles of CYP1A1, it is necessary to develop isoform-specific probe(s) for highly selective and sensitive detection of the real activities of CYP1A1 in complex biological systems.

In the last decade, activity-based optical probes offer promising tools to monitor the real activities of target enzymes under physiological conditions, due to their high selectivity, non-destructiveness, as well as the capacity for high-throughput real-time monitoring. ${ }^{7 c, 14}$ Among various types of optical imaging techniques, two-photon microscopy (TPM), by virtue of its higher sensitivity, real-time spatial high-resolution imaging, and reduced phototoxicity or photodamage to biological samples, has shed new light on real-time monitoring and imaging of target enzyme activity. ${ }^{15}$ Therefore, it is highly desirable to take advantage of TPM imaging for precise detection of the real activities of target enzyme(s), especially in complex biological systems. ${ }^{16}$

CYP1A1 and CYP1A2 share high homology (72.55\%) in amino acid sequence and show overlapped substrates and inhibitor spectra. ${ }^{5}$ To the best of our knowledge, isoformspecific probes for CYP1A1 have not been reported yet. In this study, we aimed to develop a CYP1A1-specific probe which can be used to explore the biological functions and physiological roles of this isoenzyme in living systems. From the 3D structures of two human CYP1A isoforms, CYP1A1 has a rather planar active site with a cavity volume of $524 \AA$, which is larger than that of CYP1A2 (375 $\AA^{\circ} .{ }^{17}$ Furthermore, both CYP1A1 and CYP1A2 are typical dealkylating enzymes; CYP1A2 shows a certain predilection for demethylation, while CYP1A1 can catalyze $O$-dealkylation of relatively large groups, such as $O$-ethyl or $O$-chloroethyl. ${ }^{18}$ These findings indicate that the catalytic cavity of CYP1A1 is larger and more flexible than that of CYP1A2, while CYP1A1 can catalyze substrates with relatively large $O$-alkyl groups. These previous findings prompted us to develop an isoform-specific probe for CYP1A1 via adjusting the leaving groups (such as the $O$-alkyl group).
Recently, we reported that 4-methoxy-1,8-naphthalimide and its derivatives are good substrates of CYP1A, but they could not distinguish between CYP1A1 and CYP1A2. ${ }^{19}$ Herein, to design and develop an isoform specific two-photon fluorescent probe for CYP1A1, a practical strategy was employed via adjusting the local structure of the reaction site on this known CYP1A fluorescent substrate. To this end, 4-hydroxy-1,8-naphthalimide (HN) was selected as the basic fluorophore, while a series of $O$-alkylated $\mathbf{H N}$ derivatives were designed and screened. Following both molecular docking-based virtual screening and reaction phenotypingbased experimental screening, $N$-(4-butyl)-4-chloroethoxy1,8-naphthalimide (NBCeN) displayed good reactivity and high selectivity towards CYP1A1 over other CYP isoforms including CYP1A2. Under physiological conditions, the chloroethyl group of NBCeN could be readily cleaved by CYP1A1, leading to the release of $N$-(4-butyl)-4-hydroxy1,8-naphthalimide (NBHN). As a result, CYP1A1-mediated NBCeN-O-dechloroethylation triggered remarkable changes in both colour and fluorescence emission (Scheme 1). Based on these findings, we further characterized the features of this isoform-specific probe for CYP1A1, and explored the feasibility and practicability of its use in complex biological systems.

\section{Results and discussion}

\section{Design and synthesis of NBCeN}

Given that the active cavity of CYP1A1 is larger than that of CYP1A2 and that CYP1A1 prefers dealkylation of larger $O$-alkyl groups, a library of $O$-alkylated $\mathbf{H N}$ derivatives were purposely designed and then evaluated for their potential as good substrates for CYP1A1 through molecular docking-based virtual screening and reaction phenotyping-based experimental screening. ${ }^{20}$ Representative structures and chemical characteristics are depicted in Fig. S1 (ESI $\dagger$ ), including methyl (1), ethyl (2), propyl (3), isopropyl (4), butyl (5), chloroethyl (6), chloropropyl (7), bromoethyl (8), five-membered ring (9), sixmembered ring (10), benzene ring (11), thiophene (12) and pyridine (13). The molecular docking results demonstrated that the alkyl groups of compounds (1)-(8) could orient towards the active sites of CYP1A1 and CYP1A2 (with catalytically reactive distances from the proton-iron of CYP450 ranging from 2.5 to $5.5 \AA$ A). In particular, compound (6) could

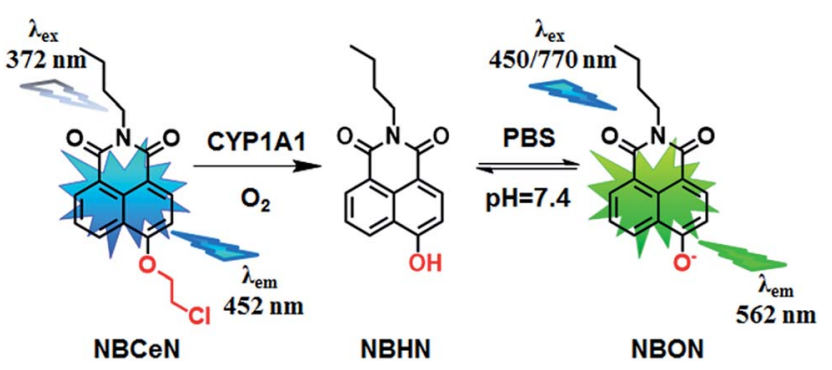

Scheme 1 Structure of NBCeN and its fluorescence response towards CYP1A1. 
orient itself markedly better in the active site of CYP1A1 than that of CYP1A2 (Tables S1 and S2, ESI $\dagger$ ). After then, reaction phenotyping screening using a panel of human CYPs revealed that $O$-alkylated $\mathbf{H N}$ derivatives (1)-(8) displayed good reactivity towards CYP1A, but most of them could also be rapidly $O$-demethylated by other CYPs including CYP2B6, CYP2D6 and CYP3A4. Among these derivatives, $N$-(4-butyl)-4-chloroethoxy1,8-naphthalimide $(6, \mathbf{N B C e N})$ displayed good reactivity and high selectivity towards CYP1A1 over other CYPs isoforms, especially CYP1A2 (Table S3, ESI $\dagger$ ). The chloroethoxy group of NBCeN could be selectively cleaved by CYP1A1, leading to the release of $\mathrm{N}$-(4-butyl)-4-hydroxy-1,8-naphthalimide (NBHN). The chemical structure and ratiometric fluorescence mechanism of the probe NBCeN was depicted in Scheme 1. NBCeN could be readily synthesized using NBHN and 1-chloro2-iodoethane as the starting materials (Scheme S1, ESI $\dagger$ ), while its structure was fully characterized by ${ }^{1} \mathrm{H}-\mathrm{NMR},{ }^{13} \mathrm{C}-\mathrm{NMR}$ and HRMS (ESI $\dagger$ ).

\section{Spectral properties of NBCeN towards CYP1A1}

NBCeN was found readily dealkylated upon addition of CYP1A1, or CYP1A1-containing tissue preparations including human liver microsomes (HLM) and lung microsomes (HLuM). Meanwhile, a single metabolite NBHN was identified by comparison of LC retention times, UV and MS spectra with the help of a standard (Fig. S2, ESI $\dagger$ ). Notably, the formation of NBHN was time-, NADPH-, and enzyme-dependent. As shown in Fig. 1a and b, NBCeN-O-dechloroethylation brought a remarkable fluorescence enhancement at $562 \mathrm{~nm}$ (for NBHN), accompanied by a gradual decrease in the emission peak at $452 \mathrm{~nm}$ (for NBCeN). The large red shift $(110 \mathrm{~nm})$ in the emission behaviour led to a striking change of the reaction from colourless to yellow, indicating that NBCeN could serve as a "naked-eye" colorimetric indicator for target enzyme(s). Furthermore, the effects of organic solvent and $\mathrm{pH}$ on the fluorescence response of NBCeN and NBHN were also studied. DMSO at low concentration (0.5\%) did not have any obvious effects on the formation rate of NBHN (Fig. S3, ESI $†$ ). In addition, while NBHN was quite stable over the $\mathrm{pH}$ range of $7.0-10.0, \mathbf{N B C e N}$ was stable in a much wider $\mathrm{pH}$ range between 2.0 and 10.0 (Fig. S4, ESI $\dagger$ ). Together, these results demonstrated that NBCeN could function properly under physiological conditions ( $\mathrm{pH}$ 7.4) at $37^{\circ} \mathrm{C}$.
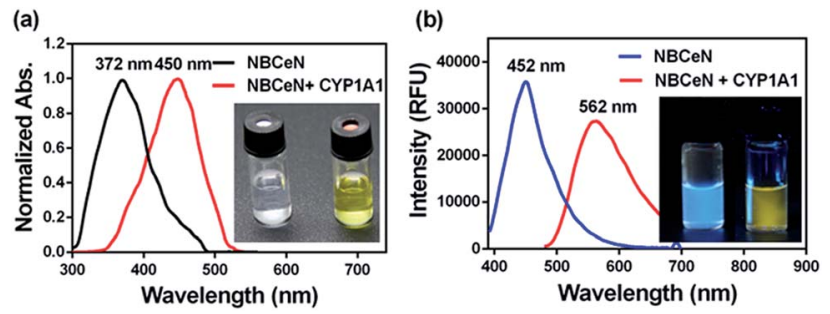

Fig. 1 (a) Normalized absorption spectra of NBCeN $(20 \mu \mathrm{M})$ upon addition of CYP1A1 (100 nM). (b) Emission spectra of NBCeN $(20 \mu \mathrm{M})$ upon addition of CYP1A1 (100 nM).

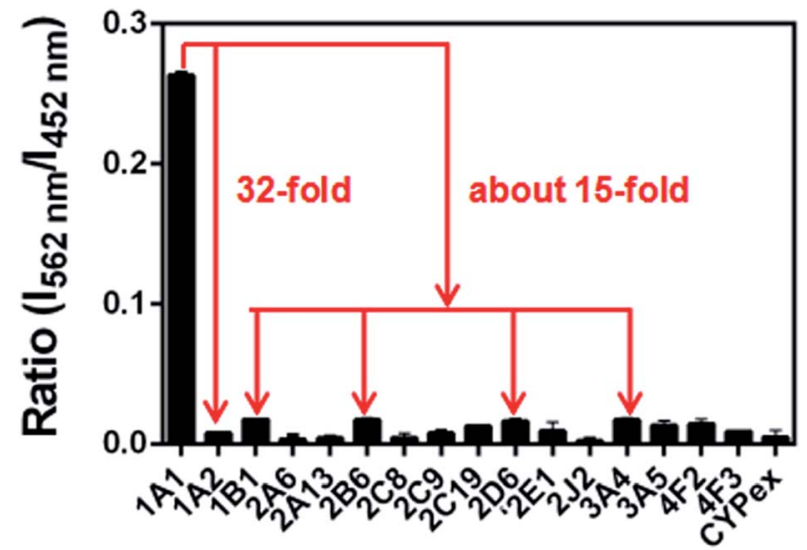

Fig. 2 Fluorescence responses of NBCeN $(20 \mu \mathrm{M})$ towards various species of enzymes in human tissue microsomes.

\section{Isoform specificity of NBCeN towards CYP1A1}

The selectivity of NBCeN towards CYP1A1 was then examined under physiological conditions ( $\mathrm{pH} 7.4$ at $37^{\circ} \mathrm{C}$ ). A series of CYP isoforms were used to evaluate their possible participation in the formation of NBHN. As shown in Fig. 2, among all CYP isoforms examined, only CYP1A1 triggered a remarkable change in the fluorescence spectrum. Indeed, there was 32-fold and 15-fold difference in fluorescence intensity for CYP1A1 compared to CYP1A2 and other CYPs (e.g. 1B1, 2B6, 2D6 and 3A4), respectively. Moreover, the fluorescence response of NBCeN to various biologically relevant small molecules was also evaluated to further explore its anti-interference ability in complex biological systems. As shown in Fig. S5 (ESI $\dagger$ ), the excellent responsiveness of NBCeN towards CYP1A1 was not affected in the presence of common biological metallic ions or amino acids in human tissues or fluids. These results revealed that NBCeN was highly selective for CYP1A1 over other biologically relevant species. To further validate the selectivity of NBCeN in complex biological systems, chemical inhibition assays were conducted in human tissue preparations using selective inhibitors of major human CYP isoforms. As shown in Fig. S6 (ESI $\dagger$ ), the formation of NBHN could be potently inhibited by ABT (a broad CYP inhibitor) and resveratrol (a selective inhibitor of CYP1A1), while furafylline (a potent inhibitor of CYP1A) exhibited lower inhibitory effects on NBCeN-O-dechloroethylation than resveratrol. ${ }^{21}$ In contrast, inhibitors of other CYP isoforms exhibited minor inhibitory effects on this (CYP1A1 mediated) biotransformation. All these results supported NBCeN as a highly selective substrate for human CYP1A1.

\section{Fluorescence sensing behaviour of NBCeN towards CYP1A1}

To accurately measure the enzyme activity, the linear response ranges for CYP1A1 quantification with $\mathbf{N B C e N}$ as a probe substrate were evaluated under physiological conditions. Time course studies showed that the formation rates of NBHN in CYP1A1 were linearly related to the reaction time, and the ratio of fluorescence intensities (562 nm/452 nm) showed good 
linearity $\left(R^{2}>0.99\right)$ with the incubation time up to $30 \mathrm{~min}$ (Fig. S7, ESI $\dagger$ ). Therefore, further assays related to quantitative analysis for CYP1A1 were conducted within $30 \mathrm{~min}$. The responses of NBCeN towards target enzymes with different concentrations were also determined. An increased CYP1A1 concentration resulted in a remarkable enhancement in fluorescence at $562 \mathrm{~nm}$, while the original emission peak of NBCeN at $452 \mathrm{~nm}$ decreased gradually. As shown in Fig. 3, a good linear relationship $\left(R^{2}>0.99\right)$ between the fluorescence intensity ratio (562 nm/452 nm) and enzyme concentrations in the range of 0 to $200 \mathrm{nM}$ were presented. The corresponding detection limit of NBCeN for CYP1A1 was evaluated as $2.5 \mathrm{nM}$ (Fig. S8, ESI $\dagger$ ). The excellent selectivity and sensitivity of the fluorescencebased assay implied that NBCeN could serve as an efficient tool for the specific detection of CYP1A1 enzyme activity in biological samples.

It is well-known that kinetic behavior is very crucial for the quantitative applications of activity-based probe substrates. ${ }^{22}$ In this study, fluorescence intensity was used to characterize the enzymatic kinetics of NBCeN-O-dechloroethylation in different enzyme sources including HLM, HLuM, CYP1A1 and CYP1A2. NBCeN-O-dechloroethylation in these enzyme sources displayed typical Michaelis-Menten kinetics, as evidenced by the corresponding Eadie-Hofstee plots (Fig. 4). As shown in Table 1, NBCeN-O-dechloroethylation in both recombinant CYP1A and human tissue preparations displayed very high affinity $\left(K_{\mathrm{m}}<2.0\right.$ $\mu \mathrm{M})$. However, in contrast to CYP1A2, CYP1A1 showed good reactivity in $\mathbf{N B C e N - O}$-dechloroethylation. Indeed, there was an estimated more than 1000-fold difference in catalytic efficacy and inherent clearance $\left(K_{\text {cat }} / K_{\mathrm{m}}\right)$ of NBCeN-O-dechloroethylation between CYP1A1 and CYP1A2. These results suggested that NBCeN was a highly specific probe for CYP1A1. Furthermore, HLuM displayed much lower reactivity for NBCeN-O-dechloroethylation than HLM, which could be attributed to the low protein levels of CYP1A1 in human lung tissues. Together, NBCeN appears to be a good substrate for CYP1A1 but not CYP1A2. The excellent selectivity and high affinity of NBCeN for CYP1A1 inspired us to use this probe for
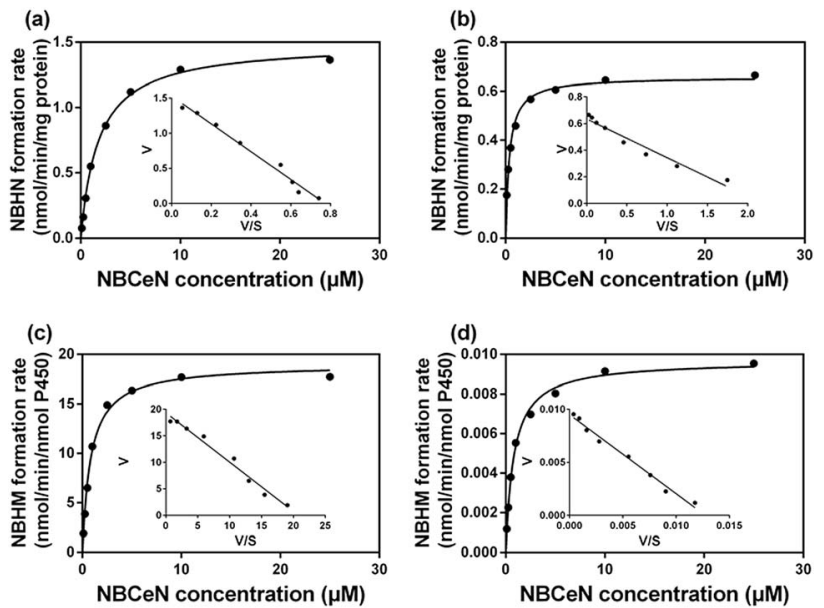

Fig. 4 Michaelis-Menten plots of NBCeN-O-dechloroethylation in human liver microsomes (a) and human lung microsomes (b), CYP1A1 (c) and CYP1A2 (d). The corresponding Eadie-Hofstee plot is shown as an inset.

evaluation of CYP1A1 activity in biological samples containing multiple enzymes.

\section{Quantification of CYP1A1 in human tissue preparations}

To further evaluate the application of $\mathbf{N B C e N}$ as a probe, we next assessed the catalytic activities of CYP1A1 in individual HLM samples. The catalytic activities of CYP1A1 mediated NBCeN-O-dechloroethylation in a panel of twelve HLMs from different individuals were measured (Fig. 5a). Compared with the large differences in expression of CYP1A2, about 4-fold individual differences in CYP1A1 catalytic activity were observed, which agreed well with previously reported interindividual variability in CYP1A1 activity. ${ }^{23}$ In order to determine whether the formation rate of NBHN reflected the catalytic activities of CYP1A1 in these individual samples, we conducted a correlation analysis between the catalytic activities and the protein levels of CYP1A1 determined by a proteomics-based approach. As shown in Fig. 5b, a strong correlation with a high (a)

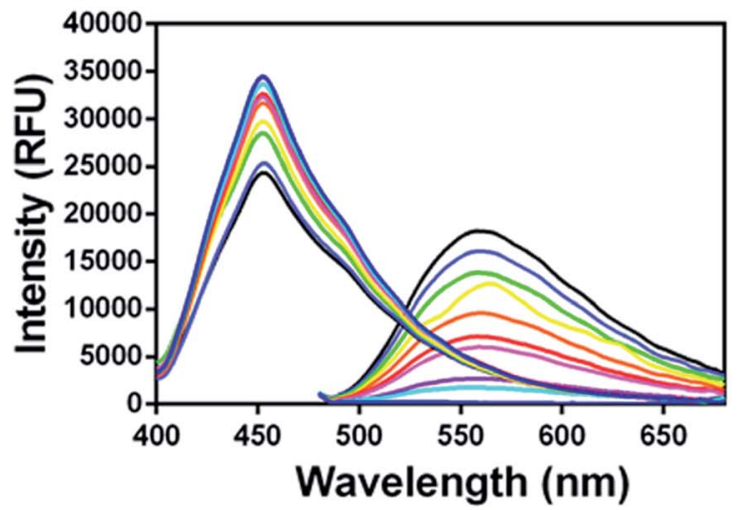

(b)

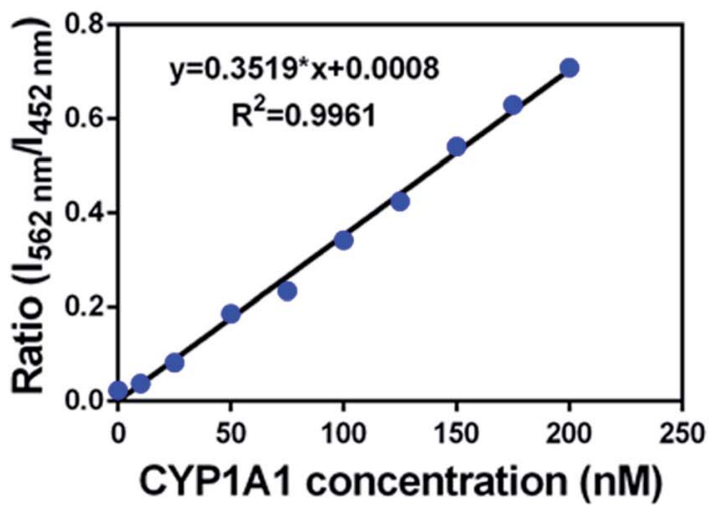

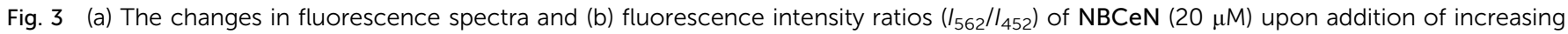
concentrations of CYP1A1 (0-200 nM) in PBS-acetonitrile $(\mathrm{v} / \mathrm{v}=1: 1, \mathrm{pH} 7.4)$ at $37^{\circ} \mathrm{C} . \lambda_{\mathrm{ex}}=372 / 452 \mathrm{~nm}$. 
Table 1 Kinetic parameters of $\mathrm{NBCeN}-\mathrm{O}$-dechloroethylation determined in different enzyme sources ${ }^{a}$

\begin{tabular}{lrrr}
\hline Enzyme sources & \multicolumn{1}{c}{$K_{\text {cat }}$} & $K_{\mathrm{m}}$ & \multicolumn{1}{c}{$K_{\text {cat }} / K_{\mathrm{m}}$} \\
\hline HLM & 1.49 & 1.79 & 837.07 \\
HLuM & 0.66 & 0.36 & 1805.56 \\
CYP1A1 & 18.99 & 0.84 & 22607.14 \\
CYP1A2 & 0.01 & 0.81 & 20.12
\end{tabular}

${ }^{a} K_{\text {cat }}$ values were in $\mathrm{nmol} \mathrm{min}^{-1} \mathrm{mg}^{-1}$ protein for liver and lung microsomes, or in nmol min ${ }^{-1} \mathrm{nmol}^{-1}$ CYP for CYP1A1 and CYP1A2. The range of substrate concentrations was 0.1 to $25 \mu \mathrm{M}$. Each value was the mean \pm S.D. of determinations performed in duplicate.

correlation parameter $\left(R^{2}=0.9033, P<0.0001\right)$ was presented between the $O$-dechloroethylation rates of $\mathbf{N B C e N}$ and the protein levels of CYP1A1 in a panel of 12 HLM samples. These findings strongly suggested that NBCeN could be used to measure the enzyme activity of CYP1A1 in complex biological systems.

\section{Rapid screening of CYP1A1 modulators}

Encouraged by the above mentioned findings, we explored the potential use of $\mathbf{N B C e N}$ as a fluorescent substrate for the screening of CYP1A1 inhibitors. One known chemical inhibitor of CYP1A1 ( $\alpha$-naphthoflavone) was used to evaluate its inhibitory effects toward CYP1A1 in both HLM and recombinant CYP1A1. As expected, this inhibitor inhibited CYP1A1-mediated NBCeN-O-dechloroethylation in a dose-dependent manner with similar inhibitory tendencies and $\mathrm{IC}_{50}$ values in these different enzyme sources (Fig. S11, ESI $\dagger$ ), indicating that HLM could be used as an enzyme source instead of the more expensive recombinant CYP1A1 in such assays. In addition, NBCeN could also be used to characterise CYP1A1 inducers using fluorescence based high-throughput screening (HTS) assays. To explore this potential use, a known CYP1A1 inducer (a)

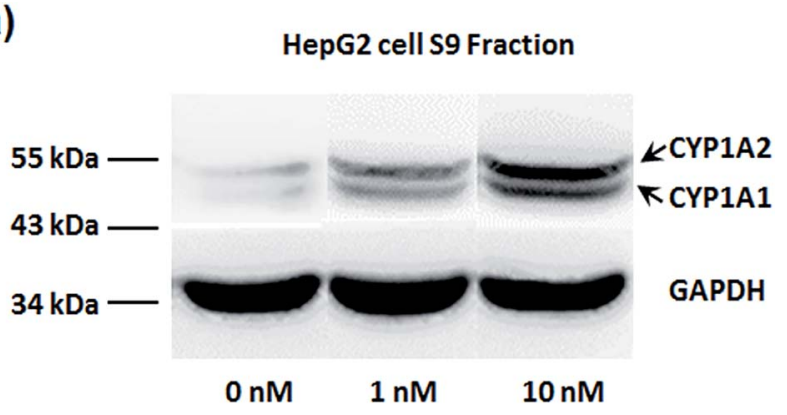

(b)

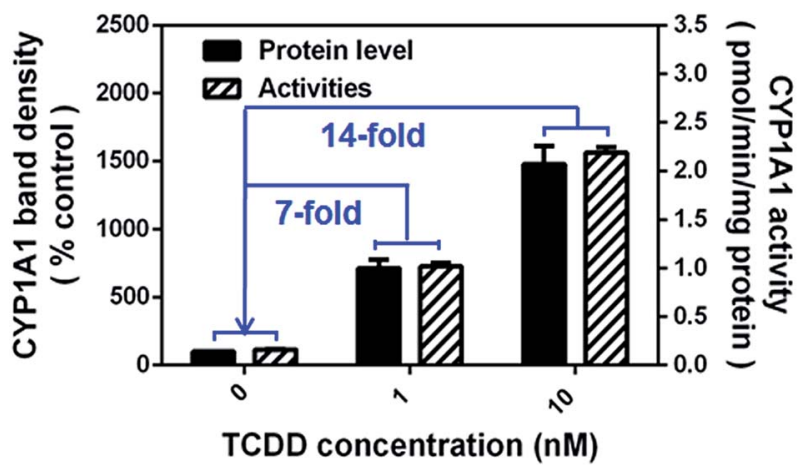

Fig. 6 (a) The levels of the CYP1A1 protein in cell homogenates prepared from HepG2 pre-treated with $\operatorname{TCDD}(0,1,10 \mathrm{nM})$ were analyzed by western blot analysis. Data are shown as the mean \pm S.D. $(n=3)$; (b) comparison of the catalytic activities and levels of CYP1A1 in HepG2 cells pre-treated with TCDD $(0,1,10 \mathrm{nM})$.

(2,3,7,8-tetrachlorodibenzo- $p$-dioxin, TCDD) was used to evaluate its effects on the expression and activity of CYP1A1 in HepG2 cells. ${ }^{24}$ As shown in Fig. 6, three different concentrations of TCDD (0, 1 and $10 \mathrm{nM})$ were used to stimulate the expression of CYP1A1. After co-incubation with TCDD for three days, there was a 14-fold increase in CYP1A1 activity in the cell homogenate (a)

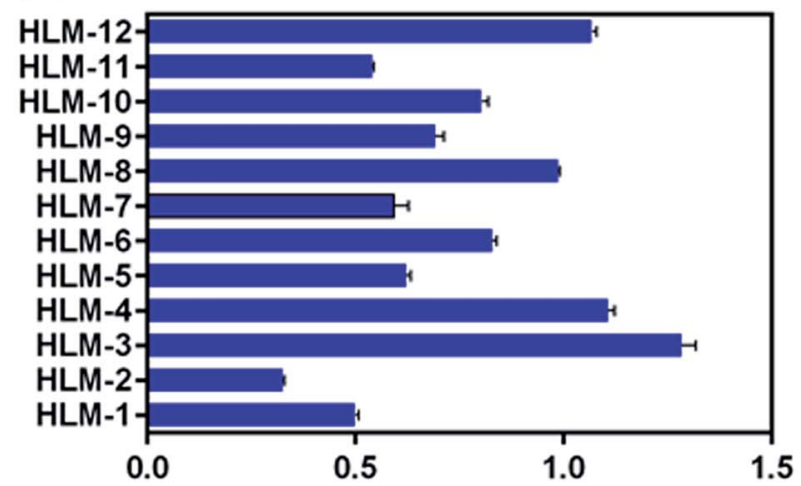

\section{CYP1A1 O-dechloroethylation for $\mathrm{NBCeN}$ ( $\mathrm{nmol} / \mathrm{min} / \mathrm{mg}$ protein)}

(b)

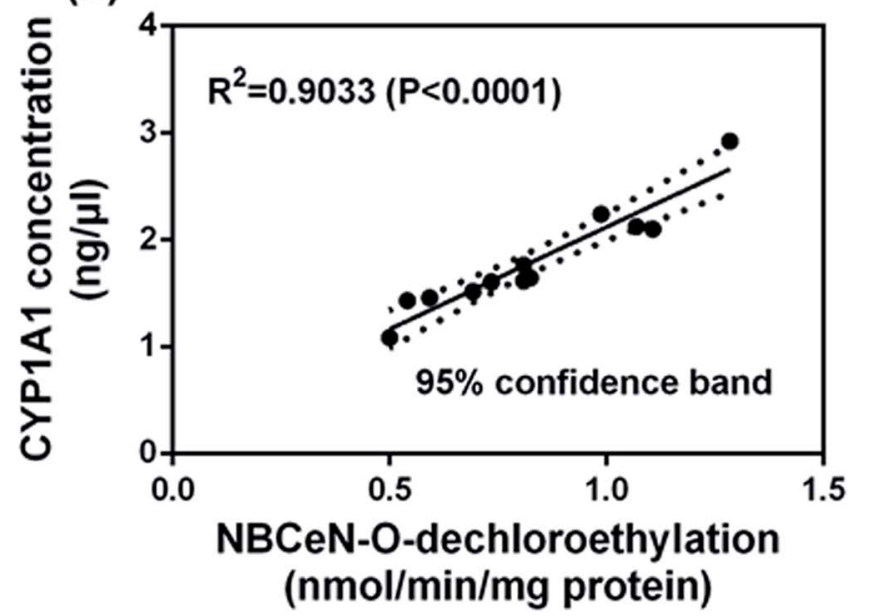

Fig. 5 (a) The catalytic activities of NBCeN in a panel of twelve individual HLMs. (b) Correlation analysis between NBCeN (10 $\mu M$ ) $O$-dechloroethylation and the level of CYP1A1 in a panel of individual HLM samples $(n=12)$. The spectra were measured in PBS-acetonitrile $(\mathrm{v} / \mathrm{v}=1: 1, \mathrm{pH}$ 7.4). 
upon addition of $10 \mathrm{nM}$ TCDD (Fig. 6b). Furthermore, the elevated CYP1A1 activities were consistent with the increased protein levels of CYP1A1 determined by western blot analysis (Fig. 6a and b). These findings suggested that NBCeN could be used for high-throughput screening of potential CYP1A1 modulators using complex tissue or cell preparations as enzyme sources.

\section{Bioimaging of CYP1A1 in living cells}

Encouraged by the above mentioned findings, we next examined NBCeN for its application in bioimaging of endogenous CYP1A1 in living A549 and SKOV3 cells. ${ }^{25}$ Prior to the bioimaging of endogenous CYP1A1 in living cells, MTT assays were performed to evaluate the cytotoxicity of NBCeN towards A549 and SKOV3 cells. The results indicated that NBCeN exhibited relatively low toxicity towards the human cells examined, and the cell viabilities were about $80 \%$ upon addition of NBCeN $(50 \mu \mathrm{M})$ at $37^{\circ} \mathrm{C}$ for $48 \mathrm{~h}$ (Fig. S13, ESI $\left.\dagger\right)$. We also investigated the induction effects of NBCeN on endogenous CYP1A1 in living cells. As shown in Fig. S14, $\dagger$ although the mRNA levels of CYP1A1 in A549 cells could be induced by NBCeN following $2 \mathrm{~h}$ incubation, the protein levels of CYP1A1 did not change following $2 \mathrm{~h}$ incubation. In these cases, NBCeN $(50 \mu \mathrm{M})$ was co-incubated with A549 and SKOV3 cells and the confocal fluorescence images were recorded both in one and two-photon modes within 2 h. As shown in Fig. 7 and 8 , after loading with $\mathbf{N B C e N}(50 \mu \mathrm{M})$ for $1 \mathrm{~h}$ at $37^{\circ} \mathrm{C}$, A549 and SKOV3 cells exhibited both single-photon and two-photon excited intense intracellular fluorescence in the blue and green channel (Fig. 7a-e and 8a-e), corresponding to fluorescence of the substrate at $452 \mathrm{~nm}$ and fluorescence of the product at $562 \mathrm{~nm}$. In sharp contrast, upon pre-treatment of cells with the CYP1A1 selective inhibitor resveratrol $(50 \mu \mathrm{M})$, a significant fluorescence decrease in green emission and a concomitant enhancement in the blue-channel were observed (Fig. $7 \mathrm{f}-\mathrm{j}$ and $8 \mathrm{f}-\mathrm{j}$ ). It is evident that the changes in fluorescence response depend on the degree of intracellular CYP1A1-mediated NBCeN-O-dechloroethylation in various cell types. These findings suggested that $\mathbf{N B C e N}$ was cell membrane permeable and has low cell toxicity, and could be applied to both singlephoton and two-photon-excited bio-imaging and for sensing the real-time activity of CYP1A1 in living cells.

\section{D depth imaging of CYP1A1 in rat liver tissues}

The utility of this probe in tissue imaging was further investigated. Prior to tissue imaging, the specificity of NBCeN towards CYP1A1 in rat liver was evaluated. As shown in Fig. S16 (ESI $\dagger$ ), NBCeN-O-dechloroethylation was significantly inhibited by known CYP1A1 inhibitors in rat liver preparation, validating CYP1A1 in rat liver as the key enzyme responsible for $\mathbf{N B C e N}$ dealkylation. The liver was isolated from a 7 week-old rat, and liver slices were incubated with $50 \mu \mathrm{M} \mathrm{NBCeN}$ for $1 \mathrm{~h}$ at $37^{\circ} \mathrm{C}$. As shown in Fig. 9, these TPM images revealed strong fluorescence responses in both blue and green channels at a depth of $80 \mu \mathrm{m}$, indicating that CYP1A1 was abundant in the rat liver. Several little and anomalous bright fluorescence signals in green channels have also been observed in TPM images of a fresh rat liver slice stained with or without NBCeN (Fig. 9 and $\mathrm{S} 17 \dagger$ ), which may be attributed to the endogenous matrix molecules in rat liver tissue that can be excited under the detection conditions. All these results indicated that NBCeN displayed good tissue penetrability and was appropriate for direct two-photon fluorescent depth imaging of CYP1A1 in living tissues.

\section{Docking simulation of NBCeN into CYP1A1 and CYP1A2}

A molecular docking simulation was also carried out to explore the difference in NBCeN-O-dechloroethylation between CYP1A1
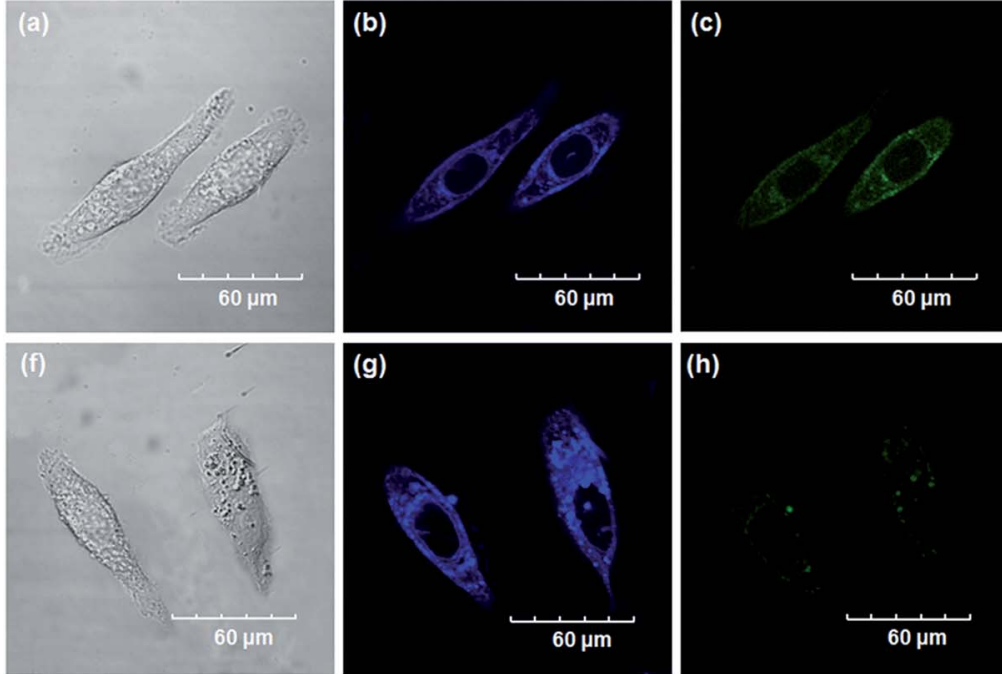
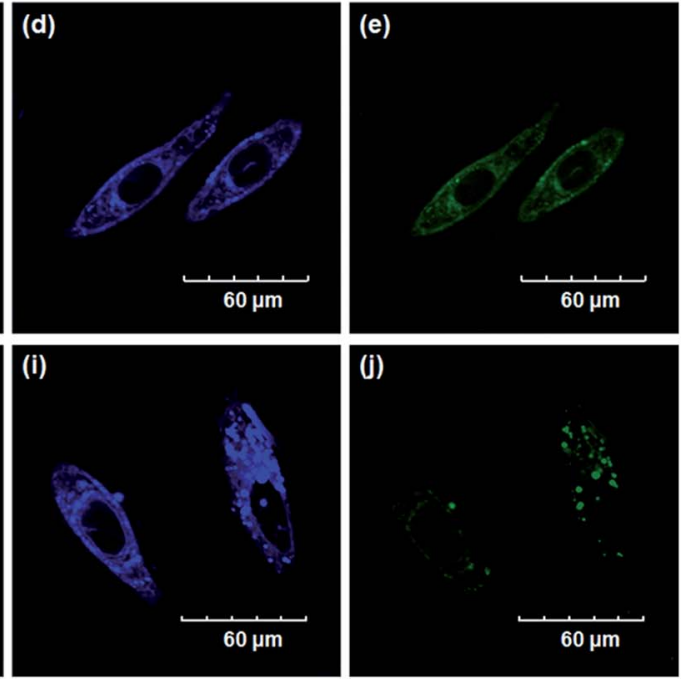

Fig. 7 Confocal fluorescence images of A549 cells. Cells incubated with NBCeN (50 $\mu \mathrm{M})$ for $1 \mathrm{~h}$ (top); cells pre-treated with resveratrol (50 $\mu \mathrm{M}$ ) for $1 \mathrm{~h}$ and then incubated with NBCeN for $1 \mathrm{~h}$ (bottom). Single photon images were acquired using $405 \mathrm{~nm}$ excitation and fluorescent emission windows: (a) and (f) bright-field images; (b) and (g) blue emission channel; (c) and (h) green emission channel. Two photon images were acquired using $770 \mathrm{~nm}$ excitation and fluorescent emission windows: (d) and (i) blue $=420-460 \mathrm{~nm}$; (e) and (j) green $=495-540 \mathrm{~nm}$. Scale bar: $60 \mu \mathrm{m}$. 

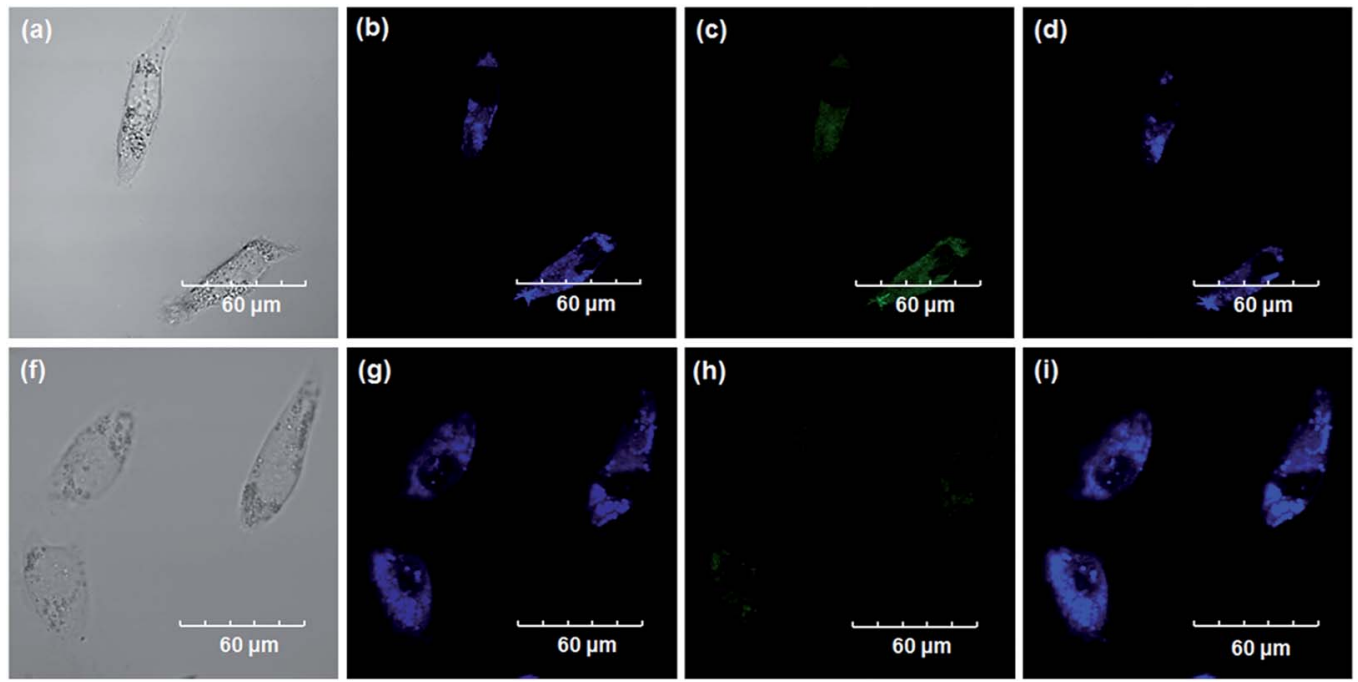

Fig. 8 Confocal fluorescence images of SKOV3 cells. Cells incubated with NBCeN (50 $\mu$ M) for $1 \mathrm{~h}$ (top); cells pre-treated with resveratrol (50 $\mu \mathrm{M})$ for $1 \mathrm{~h}$ and then incubated with NBCeN for $1 \mathrm{~h}$ (bottom). Single photon images were acquired using $405 \mathrm{~nm}$ excitation and fluorescent emission windows: (a) and (f) bright-field images; (b) and (g) blue emission channel; (c) and (h) green emission channel. Two photon images were acquired using $770 \mathrm{~nm}$ excitation and fluorescent emission windows: (d) and (i) blue $=420-460 \mathrm{~nm}$; (e) and (j) green $=495-540 \mathrm{~nm}$. Scale bar: $60 \mu \mathrm{m}$.

and CYP1A2. As shown in Fig. 10, a very complementary $\pi-\pi$ stacking interaction was formed between CYP1A1 and NBCeN (with the side chain of Phe-224), likely due to an enhanced contact of NBCeN with the active site surface of CYP1A1. ${ }^{26}$ Of note, the introduction of chloroethyl groups appeared to orient NBCeN markedly better in the active site of CYP1A1 than CYP1A2. Furthermore, the proton-iron distances between the reaction site of NBCeN and the heme of CYP1A1 (3.78 $\AA$ ) were much shorter than those in CYP1A2 (5.37 $\mathrm{A})$, suggesting that NBCeN-O-dechloroethylation could occur more readily in CYP1A1. Given that the catalytically reactive distance from the proton-iron of CYP450 is typically within $5.5 \AA{ }^{27}$ NBCeN-O-dechloroethylation is hardly likely to occur in CYP1A2. These results are concordant with the experimental results, which displayed that CYP1A1 but not CYP1A2, can catalyze NBCeN-O-dechloroethylation with a high catalytic efficacy. In addition, the hammerhead score value of the bioactive pose of NBCeN in CYP1A1 (9.583) is similar to that in CYP1A2 (8.175), both of which are in agreement with the closed $K_{\mathrm{m}}$ values for NBCeN-O-dechloroethylation in both CYP1A1 and
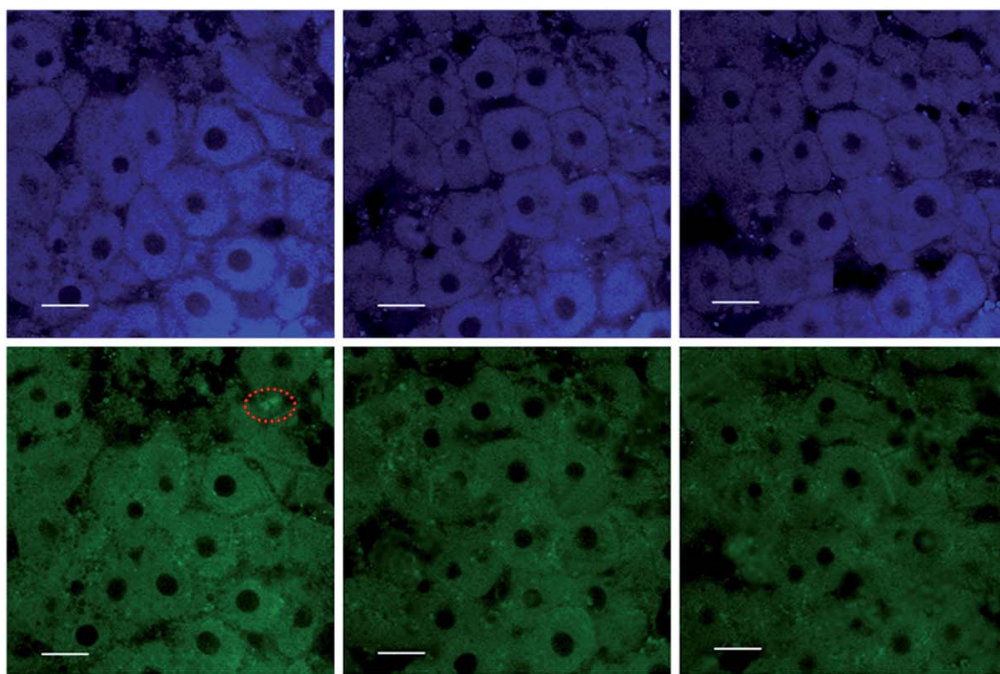

$0 \mu \mathrm{m}$

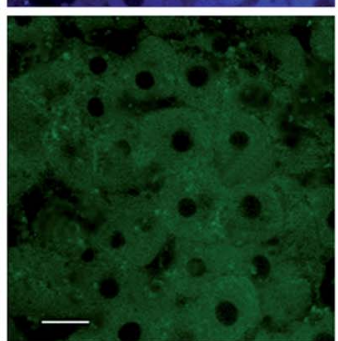

$20 \mu \mathrm{m}$

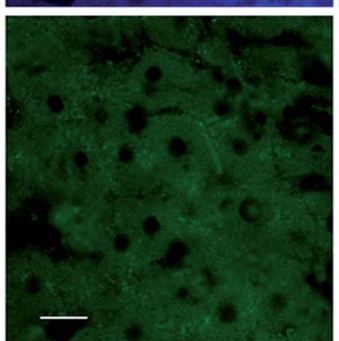

$40 \mu \mathrm{m}$
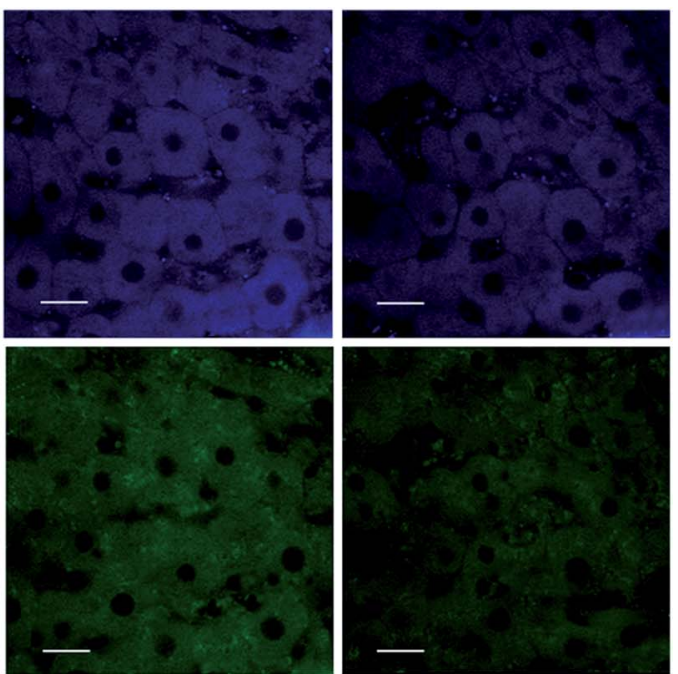

$60 \mu \mathrm{m}$

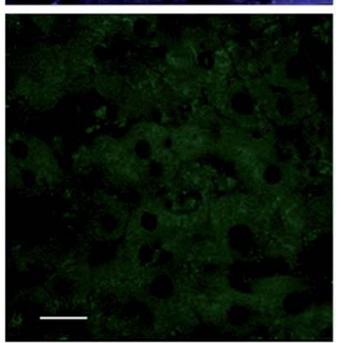

$80 \mu \mathrm{m}$

Fig. 9 TPM images of a fresh rat liver slice stained with $\mathrm{NBCeN}(20 \mu \mathrm{M})$. Images were taken at a depth of $0-80 \mu \mathrm{m}$ with magnification at $60 \times$. Two photon images were acquired using $770 \mathrm{~nm}$ excitation and fluorescent emission windows: blue $=420-460 \mathrm{~nm}$ (top); green $=495-540 \mathrm{~nm}$ (bottom). Scale bar: $30 \mu \mathrm{m}$. Several little and anomalous bright fluorescence spots in the green channels have been marked, which may be ascribed to the endogenous matrix in rat liver. 


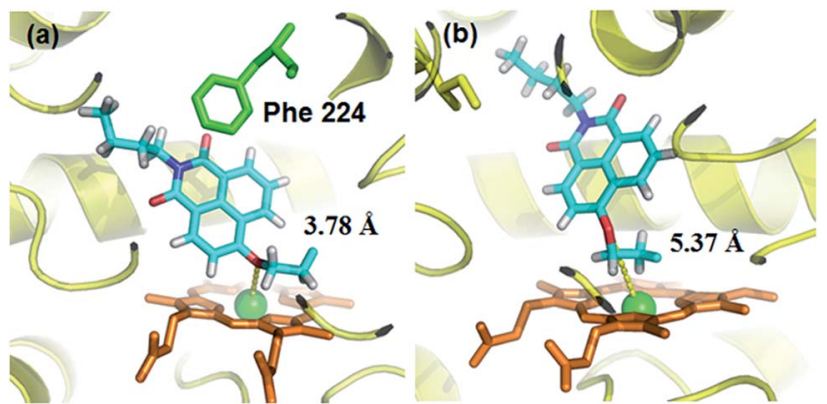

Fig. 10 Docking simulation of NBCeN into CYP1A1 (a) and CYP1A2 (b). Heme and iron atoms are colored with brown and green, respectively.

CYP1A2. These findings may partially explain why NBCeN is a good substrate for CYP1A1 but a poor substrate for CYP1A2.

\section{Conclusions}

In summary, a practical strategy was used to design an isoformspecific two-photon fluorescent probe for highly selective and sensitive detection of CYP1A1 for the first time. The isoformspecific fluorescent probe was designed via local modification of the reaction site on a known CYP1A substrate, on the basis of subtle differences in the catalytic cavity and substrate preference between CYP1A1 and other isoforms in the CYP superfamily. Following molecular docking-based virtual screening and reaction phenotyping-based experimental screening of various $O$-alkylated $\mathbf{H N}$ derivatives, NBCeN displayed the best combination of selectivity, sensitivity, high affinity and ratiometric fluorescence response following CYP1A1-catalyzed $O$-dechloroethylation. This newly developed isoform-specific probe could be used to real-time monitor the real activities of CYP1A1 in complex biological systems, and it displayed great potential for high-throughput screening of CYP1A1 modulators using cell or tissue preparations as enzyme sources. Meanwhile, ratiometric TPM bioimaging of NBCeN and its metabolite revealed that this probe could serve as an effective imaging tool to monitor endogenous CYP1A1 with high resolution and sensitivity in living cells and tissues. All these findings demonstrated that the newly developed probe could be reliably used for the precise, rapid and highly sensitive detection of CYP1A1 in biomedical and bioanalytical fields, which held a great promise for exploring the biological and physiological roles of endogenous CYP1A1 in living systems. Furthermore, the strategies used in this study are very helpful for the design, screening and optimization of isoform specific probe substrates for target enzyme(s), which opens up a new avenue for the development of isoform-specific probes for other enzymes, especially for hydrolases and lyases.

\section{Acknowledgements}

We gratefully acknowledge Dr Xinyue Zhu from Lanzhou University for measurement of two-photon excitation spectra of the probe and its product. This work was supported by the
National Key Research and Development Program of China (2016YFC1303900), the National Basic Research Program of China (2013CB531805), NSF of China (81473181, 81573501, 21572029), and the State Key Laboratory of Fine Chemicals (KF1504 and KF1408).

\section{Notes and references}

1 (a) Y. K. Paik, S. K. Jeong, G. S. Omenn, M. Uhlen, S. Hanash, S. Y. Cho, H. J. Lee, K. Na, E. Y. Choi, F. Yan, F. Zhang, Y. Zhang, M. Snyder, Y. Cheng, R. Chen, G. Marko-Varga, E. W. Deutsch, H. Kim, J. Y. Kwon, R. Aebersold, A. Bairoch, A. D. Taylor, K. Y. Kim, E. Y. Lee, D. Hochstrasser, P. Legrain and W. S. Hancock, Nat. Biotechnol., 2012, 30, 221-223; (b) U. Kusebauch, D. S. Campbell, E. W. Deutsch, C. S. Chu, D. A. Spicer, M. Y. Brusniak, J. Slagel, Z. Sun, J. Stevens, B. Grimes, D. Shteynberg, M. R. Hoopmann, P. Blattmann, A. V. Ratushny, O. Rinner, P. Picotti, C. Carapito, C. Y. Huang, M. Kapousouz, H. Lam, T. Tran, E. Demir, J. D. Aitchison, C. Sander, L. Hood, R. Aebersold and R. L. Moritz, Cell, 2016, 166, 766-778.

2 D. Ramskold, E. T. Wang, C. B. Burge and R. Sandberg, PLoS Comput. Biol., 2009, 5, e1000598.

3 I. Schomburg, A. Chang, S. Placzek, C. Sohngen, M. Rother, M. Lang, C. Munaretto, S. Ulas, M. Stelzer, A. Grote, M. Scheer and D. Schomburg, Nucleic Acids Res., 2013, 41, D764-D772.

4 G. M. Simon and B. F. Cravatt, J. Biol. Chem., 2010, 285, 11051-11055.

5 (a) C. Wei, R. J. Caccavale, E. H. Weyand, S. Chen and M. M. Iba, Cancer Lett., 2002, 178, 25-36; (b) L. Xu, A. P. Li, D. L. Kaminski and M. F. Ruh, Chem.-Biol. Interact., 2000, 124, 173-189.

6 (a) J. C. Willey, E. L. Coy, M. W. Frampton, A. Torres, M. J. Apostolakos, G. Hoehn, W. H. Schuermann, W. G. Thilly, D. E. Olson, J. R. Hammersley, C. L. Crespi and M. J. Utell, Am. J. Respir. Cell Mol. Biol., 1997, 17, 114124; (b) A. Sumida, S. Fukuen, I. Yamamoto, H. Matsuda, M. Naohara and J. Azuma, Biochem. Biophys. Res. Commun., 2000, 267, 756-760; (c) M. Degawa, M. Nakayama, Y. Konno, K. Masubuchi and Y. Yamazoe, Biochim. Biophys. Acta, 1998, 1379, 391-398.

7 (a) L. Feng, Z. M. Liu, L. Xu, X. Lv, J. Ning, J. Hou, G. B. Ge, J. N. Cui and L. Yang, Chem. Commun., 2014, 50, 1451914522; (b) Z. M. Liu, L. Feng, G. B. Ge, X. Lv, J. Hou, Y. F. Cao, J. N. Cui and L. Yang, Biosens. Bioelectron., 2014, 57, 30-35; (c) Q. Jin, L. Feng, D. D. Wang, Z. R. Dai, P. Wang, L. W. Zou, Z. H. Liu, J. Y. Wang, Y. Yu, G. B. Ge, J. N. Cui and L. Yang, ACS Appl. Mater. Interfaces, 2015, 7, 28474-28481; (d) D. D. Wang, Q. Jin, L. W. Zou, J. Hou, X. Lv, W. Lei, H. L. Cheng, G. B. Ge and L. Yang, Chem. Commun., 2016, 52, 3183-3186.

8 E. P. Neve and M. Ingelman-Sundberg, Curr. Opin. Drug Discovery Dev., 2010, 13, 78-85.

9 (a) M. J. Coon, Biochem. Biophys. Res. Commun., 2005, 338, 378-385; (b) F. P. Guengerich, J. Biol. Chem., 1991, 266, 10019-10022. 
10 (a) T. Shimada and F. P. Guengerich, Cancer Res., 1991, 51, 5284-5291; (b) T. Shimada and Y. Fujii-Kuriyama, Cancer Sci., 2004, 95, 1-6; (c) N. J. Gooderham, S. Murray, A. M. Lynch, M. Yadollahi-Farsani, K. Zhao, A. R. Boobis and D. S. Davies, Drug Metab. Dispos., 2001, 29, 529-534.

11 L. S. Kaminsky and S. D. Spivack, Mol. Aspects Med., 1999, 20(137), 70-84.

12 I. Bieche, C. Narjoz, T. Asselah, S. Vacher, P. Marcellin, R. Lidereau, P. Beaune and I. de Waziers, Pharmacogenet. Genomics, 2007, 17, 731-742.

13 (a) T. Shimada, C. H. Yun, H. Yamazaki, J. C. Gautier, P. H. Beaune and F. P. Guengerich, Mol. Pharmacol., 1992, 41, 856-864; (b) L. G. Yengi, Q. Xiang, J. Pan, J. Scatina, J. Kao, S. E. Ball, R. Fruncillo, G. Ferron and C. Roland Wolf, Anal. Biochem., 2003, 316, 103-110; (c) J. A. Agundez, Curr. Drug Metab., 2004, 5, 211-224; (d) M. Stiborova, V. Martinek, H. Rydlova, T. Koblas and P. Hodek, Cancer Lett., 2005, 220, 145-154.

14 (a) H. Zhang, R. Liu, Y. Tan, W. H. Xie, H. Lei, H. Y. Cheung and H. Sun, ACS Appl. Mater. Interfaces, 2015, 7, 5438-5443; (b) J. Liang, R. T. Kwok, H. Shi, B. Z. Tang and B. Liu, ACS Appl. Mater. Interfaces, 2013, 5, 8784-8789; (c) L. Cui, Y. Zhong, W. Zhu, Y. Xu and X. Qian, Chem. Commun., 2010, 46, 7121-7123; (d) J. Zhou, L. H. Li, W. Shi, X. H. Gao, X. H. Li and H. M. Ma, Chem. Sci., 2015, 6, 4884-4888; (e) Q. Y. Gong, W. Shi, L. H. Li and H. M. Ma, Chem. Sci., 2016, 7, 788-792; (f) X. L. Sun, K. Lacina, E. C. Ramsamy, S. E. Flower, J. S. Fossey, X. H. Qian, E. V. Anslyn, S. D. Bull and T. D. James, Chem. Sci., 2015, 6, 2963-2967.

15 (a) B. Sui, X. Yue, B. Kim and K. D. Belfield, ACS Appl. Mater. Interfaces, 2015, 7, 17565-17568; (b) A. Parthasarathy, H. Y. Ahn, K. D. Belfield and K. S. Schanze, ACS Appl. Mater. Interfaces, 2010, 2, 2744-2748; (c) J. F. Zhang, C. S. Lim, S. Bhuniya, B. R. Cho and J. S. Kim, Org. Lett., 2011, 13, 1190-1193; (d) A. R. Sarkar, C. H. Heo, E. Kim, H. W. Lee, H. Singh, J. J. Kim, H. Kang, C. Kang and H. M. Kim, Chem. Commun., 2015, 51, 2407-2410; (e) X. Chen, F. Wang, J. Y. Hyun, T. Wei, J. Qiang, X. Ren, I. Shin and J. Yoon, Chem. Soc. Rev., 2016, 45, 2976-3016.

16 R. S. Foti, L. C. Wienkers and J. L. Wahlstrom, Comb. Chem. High Throughput Screening, 2010, 13, 145-158.
17 D. Dong, B. Wu, D. Chow and M. Hu, Drug Metab. Rev., 2012, 44, 192-208.

18 (a) U. M. Zanger and M. Schwab, Pharmacol. Ther., 2013, 138, 103-141; (b) U. Fuhr, A. Jetter and J. Kirchheiner, Clin. Pharmacol. Ther., 2007, 81, 270-283; (c) S. Sansen, J. K. Yano, R. L. Reynald, G. A. Schoch, K. J. Griffin, C. D. Stout and E. F. Johnson, J. Biol. Chem., 2007, 282, 14348-14355; (d) J. J. Cali, D. Ma, M. Sobol, D. J. Simpson, S. Frackman, T. D. Good, W. J. Daily and D. Liu, Expert Opin. Drug Metab. Toxicol., 2006, 2, 629-645.

19 Z. R. Dai, G. B. Ge, L. Feng, J. Ning, L. H. Hu, Q. Jin, D. D. Wang, X. Lv, T. Y. Dou, J. N. Cui and L. Yang, J. Am. Chem. Soc., 2015, 137, 14488-14495.

20 A. A. Walsh, G. D. Szklarz and E. E. Scott, J. Biol. Chem., 2013, 288, 12932-12943.

21 (a) J. K. Racha, A. E. Rettie and K. L. Kunze, Biochemistry, 1998, 37, 7407-7419; (b) M. F. Yueh, M. Kawahara and J. Raucy, Toxicol. in Vitro, 2005, 19, 275-287; (c) K. L. Kunze and W. F. Trager, Chem. Res. Toxicol., 1993, 6, 649-656.

22 (a) A. Jaworska, L. E. Jamieson, K. Malek, C. J. Campbell, J. Choo, S. Chlopicki and M. Baranska, Analyst, 2015, 140, 2321-2329; (b) G. B. Ge, J. Ning, L. H. Hu, Z. R. Dai, J. Hou, Y. F. Cao, Z. W. Yu, C. Z. Ai, J. K. Gu, X. C. Ma and L. Yang, Chem. Commun., 2013, 49, 9779-9781.

23 (a) X. X. Ding and L. S. Kaminsky, Annu. Rev. Pharmacol., 2003, 43, 149-173; (b) H. Schweikl, J. A. Taylor, S. Kitareewan, P. Linko, D. Nagorney and J. A. Goldstein, Pharmacogenetics, 1993, 3, 239-249.

24 Z. Y. Zhang, R. D. Pelletier, Y. N. Wong, M. Sugawara, N. D. Zhao and B. A. Littlefield, Biochem. Biophys. Res. Commun., 2006, 341, 399-407.

25 (a) J. V. Castell, M. T. Donato and M. J. Gomez-Lechon, Exp. Toxicol. Pathol., 2005, 57, 189-204; (b) H. Piotrowska, M. Kucinska and M. Murias, Mol. Cell. Biochem., 2013, 383, 95-102.

26 A. Wang, U. Savas, C. D. Stout and E. F. Johnson, J. Biol. Chem., 2011, 286, 5736-5743.

27 J. Jung, N. D. Kim, S. Y. Kim, I. Choi, K. H. Cho, W. S. Oh, D. N. Kim and K. T. No, J. Chem. Inf. Model., 2008, 48, 1074-1080. 